\title{
Cavity Design and Beam Simulations for the APS RF Gun
}

\author{
Advanced Photon Source \\ Michael Borland-15 November 1991
}

An earlier note discussed the preliminary design of the $1-1 / 2$ cell RF cavity for the APS RF gun. This note describes the final design, including cavity properties and simulation results from the program rfgun[7].

The basic idea for the new design was that the successful SSRL design $[1,2,3]$ could be improved upon by reducing fields that had nonlinear dependence on radius. As discussed previously, this would reduce the emittance and produce tighter momentum and time distributions. In addition, it was desirable to increase the fields in the first half-cell relative to the fields in the second half-cell, in order to allow more rapid initial acceleration, which would reduce the effects of space charge. Both of these goals were accomplished in the new design.

\section{Cavity Design}

In the previous note, I discussed how it was necessary to increase the distance between the cathode and the center of the second cell in order to allow the use of a higher accelerating gradient in the first cell. Two designs were given, one with a $4 \mathrm{~mm}$ cathode offset and another with a $6 \mathrm{~mm}$ cathode offset. Simulations with rfgun indicated that the later design gave superior performance, and hence the design presented here has a $6 \mathrm{~mm}$ cathode offset.

The design is shown in Figure 1. Table 1 gives the geometry of the design. For arcs of circles, $\mathrm{z}$ and $\mathrm{r}$ refer to the center of the arc. All arcs are connected by vertical or horizontal lines only, as required to make a continuous curve. The second cell (i.e., that part to the right of point 12) is symmetric about the point labeled 20 , except for the elongated exit beam tube.

In the previous note, I gave the off-axis field expansion for the RF fields in the gun cavity, and stated that the amount of nonlinearity could be gauged by examining two functions, defined by

$$
\mathrm{T}_{1}(\mathrm{z})=\frac{\mathrm{R}_{\mathrm{c}}^{2}}{8 \times \max \left(\mathrm{E}_{\mathrm{z}}(\mathrm{z}, \mathrm{r}=0)\right)}\left[\partial_{\mathrm{z}}^{2}+\mathrm{k}^{2}\right] \mathrm{E}_{\mathrm{z}}(\mathrm{z}, \mathrm{r}=0)
$$

and

$$
\mathrm{T}_{2}(\mathrm{z})=\frac{\mathrm{R}_{\mathrm{c}}^{2}}{8 \times \max \left(\mathrm{E}_{\mathrm{z}}(\mathrm{z}, \mathrm{r}=0)\right)}\left[\partial_{\mathrm{z}}^{3}+\mathrm{k}^{2} \partial_{\mathrm{z}}\right] \mathrm{E}_{\mathrm{z}}(\mathrm{z}, \mathrm{r}=0),
$$

where $R_{c}$ is the cathode radius. $T_{1}$ is proportional to the magnitude at $r=R_{c}$ of the $r^{3}$ term of $B_{\phi}$ and the $r^{2}$ term of $E_{z}$ terms relative to, respectively, the $r^{1}$ term of $B_{\phi}$ and the constant term of $\mathrm{E}_{\mathrm{z}}$. Similarly, $\mathrm{T}_{2}$ measures the $\mathrm{r}^{3}$ term of $\mathrm{E}_{\mathbf{r}}$ relative to the linear term, at the cathode radius. $\mathrm{T}_{1}$ is related primarily to degradation of the momentum spectrum, while $T_{2}$ is related primarily to degradation of the emittance.

Figure 2 shows various quantities related to the RF fields in the new cavity. In addition to the on-axis longitudinal electric field, the Figure shows the radial field at the cathode radius, reconstructed from off-axis expansions to third and fifth order in $r$. Note that the third and fifth order expansions are virtually identical, which attests to the extent to which nonlinear fields have been suppressed. Finally, the Figure compares $T_{1}$ and $T_{2}$ for the new cavity and the SSRL cavity.

The submitted manuscript has been authored by a contractor of the U.S. Government under contract No. W-31-109ENG-38. Accordingly, the U. S. Government retains nonexclusive, royalty-free license to publish or reproduce the published form of this
contribution, or allow others to do 50 , for U. S. Government purposes.
DISTRIBUTION OF THIS DOCUMENT IS UNLIMITED RECLIV:D

1 JUL 251995 


\section{DISCLAIMER}

This report was prepared as an account of work sponsored by an agency of the United States Government. Neither the United States Government nor any agency thereof, nor any of their employees, make any warranty, express or implied, or assumes any legal liability or responsibility for the accuracy, completeness, or usefulness of any information, apparatus, product, or process disclosed, or represents that its use would not infringe privately owned rights. Reference herein to any specific commercial product, process, or service by trade name, trademark, manufacturer, or otherwise does not necessarily constitute or imply its endorsement, recommendation, or favoring by the United States Government or any agency thereof. The views and opinions of authors expressed herein do not necessarily state or reflect those of the United States Government or any agency thereof. 


\section{DISCLAIMER}

Portions of this document may be illegible in electronic image products. Images are produced from the best available original document. 


\section{Cavity Properties}

The cavity calculations, including the field calculations shown above, have been done using URMEL[4] and checked with SUPERFISH[5]. The first cell was tuned to $2894.4 \mathrm{MHz}$ and the second cell to $2872.4 \mathrm{MHz}$, the approximate values required to obtain $2856 \mathrm{MHz}$ when the effects of waveguide and coupling cell apertures are considered[6].

Table 2 lists parameters of the first and second cells, treated individually, using values from URMEL (for which a finer mesh can be used than in SUPERFISH). The shunt impedance is defined as $\mathrm{V}_{\mathrm{i}}^{2} /\left(2 \mathrm{P}_{\mathrm{i}}\right)$, where $\mathrm{V}_{\mathrm{i}}=\int_{\text {cell }} \mathrm{E}_{\mathrm{z}}(\mathrm{z}) \mathrm{dz} . \mathrm{E}_{\mathrm{ps}}$ is the peak surface field, $\mathrm{E}_{\mathrm{c}}$ is the peak field at the cathode, and $\mathrm{E}_{\mathrm{pi}}$ is the peak, on-axis longitudinal electric field in the $i^{\text {th }}$ cavity. $\mathrm{K}_{\mathbf{i}}$ is defined as $\mathrm{U}_{\mathrm{i}} / \mathrm{E}_{\mathrm{pi}}^{2}$.

For whole-gun calculations, it is necessary to assume some value of the excitation ratio, defined as $\alpha=\mathrm{E}_{\mathrm{p} 2} / \mathrm{E}_{\mathrm{p} 1}$. The SSRL gun has $\alpha \approx 3$. The APS gun has been designed to have $\alpha \approx 1.7$. This gives the necessary momentum vs exit-time relationship for magnetic compression (see below).

The $Q$ of the cavity is given by[1]

$$
Q=Q_{2} \frac{1+\frac{K_{1}}{K_{2} \alpha^{2}}}{1+\frac{1}{\alpha^{2}} \frac{K_{1} Q_{2}}{K_{2} Q_{1}}} .
$$

Using the parameters given in the table, I obtain 15946 for the $\mathrm{Q}$ of the $\pi / 2$ structure mode.

Similarly, one can express $E_{\mathrm{p} 2}$ in terms of the total power, $\mathrm{P}$, dissipated in the cavity walls, using

$$
E_{p^{2}}=\sqrt{\frac{Q_{2}}{\omega K_{2}\left(1+\frac{1}{\alpha^{2}} \frac{K_{1} Q_{2} Q_{1}}{K_{2}}\right.}} \sqrt{P}
$$

giving $\mathrm{E}_{\mathrm{p} 2}=58.3\left(\mathrm{MV} / \mathrm{m} / \mathrm{MW}^{\frac{1}{2}}\right) \sqrt{\mathrm{P}}$. For the SSRL gun, the coefficient was 80 . The decrease reflects the decrease in shunt impedance resulting from the longer $\mathrm{RF}$ gaps in both the first and' second cell of the new gun. However, with a more uniform field level in the first and second cells, the new design produces more energetic beams for lower values of $E_{p 2}$.

\section{3 rfgun Simulation Results}

The program rfgun[7] was used as part of the design process, and has been used to simulate the APS RF gun in the absence of space-charge effects. (Preliminary calculations of the effect of space-charge in the first cell have been done using the program MASK[8]. These are discussed below.)

Figures 3 and 4 show various gun performance parameters as a function of $\mathrm{E}_{\mathrm{p} 2}$, for cathode radii of $2 \mathrm{~mm}$ and $3 \mathrm{~mm}$. The parameters in Figure 3 are for a $\pm 5 \%$ momentum spread, defined by

$$
\mathrm{p} \geq \mathrm{p}_{\max } \frac{1-\mathrm{f}}{1+\mathrm{f}}
$$

where $f=0.05$. I will refer to the beam so defined as the "useful beam". $Q_{b}$ is the charge per bunch divided by the current density, $\mathrm{J}$, which accounts for 35 to $50 \%$ of the charge exiting the gun (the fraction is higher for higher $\mathrm{E}_{\mathrm{p} 2}$ ). $\epsilon_{\mathrm{x}}=\epsilon_{\mathrm{y}}$ is the RMS geometric emittance, defined by

$$
\epsilon_{\mathrm{x}}=\sqrt{\left\langle\mathrm{x}^{2}\right\rangle\left\langle\mathrm{x}^{\prime 2}\right\rangle-\left\langle\mathrm{x}^{\prime} \mathrm{x}\right\rangle^{2}}
$$


$\mathrm{B}_{\mathrm{T}}$ is the transverse brightness, which I define as[1]

$$
\mathrm{B}_{\mathrm{T}}=\frac{2 \mathrm{Q}_{\mathrm{b}}}{\epsilon_{\mathrm{x}} \epsilon_{\mathrm{y}}} .
$$

To date, MASK simulations have been done for the first cell, for $E_{p 2}=70 \mathrm{MV} / \mathrm{m}$, and for a $2 \mathrm{~mm}$ cathode radius only. For zero current density and for $\mathrm{f}=0.05$, the emittance predicted by MASK is about $20 \%$ larger than that predicted by $\mathrm{rfgun}$. At J $=50 \mathrm{~A} / \mathrm{cm}^{2}$, the emittance is about $80 \%$ of the zero-current-density emittance (a paradoxical result that comes about because a given momentum interval contains a different initial phase interval for different current densities). At zero current density, MASK predicts an RMS radial coordinate of $1.2 \mathrm{~mm}$, an RMS radial divergence of $10.3 \mathrm{mrad}$, and a bunch length of $13.1 \mathrm{ps}$. At $\mathrm{J}=50 \mathrm{~A} / \mathrm{cm}^{2}$, these become, respectively, $1.4 \mathrm{~mm}$, $16.9 \mathrm{mrad}$, and $13.9 \mathrm{ps}$.

A future report will give results of MASK simulations of the full gun, over a wider parameter space. Results[1] of MASK simulations for the SSRL gun were that the emittance doubled when the current density was increased from essentially zero to $80 \mathrm{~A} / \mathrm{cm}^{2}$ for a cathode radius of $3 \mathrm{~mm}$. The effect of space-charge in the APS RF gun should be less than this, since the fields at the cathode are greater than in the SSRL gun. The preliminary simulations reported in the last paragraph confirm this expectation.

Figure 4 shows parameters for the entire beam and for the cavity. $P_{1}$ and $P_{2}$ are the beam power divided by the current density exiting, respectively, the first and second cells in the forward direction. $P_{b b}$ is the current-density-normalized beam power that returns to hit the plane $z=0$ (i.e., the plane of the cathode); the subscript " $\mathrm{bb}$ " stands for back-bombardment. $\mathrm{P}_{\mathrm{w}}$ is the power dissipated in the cavity walls.

Like the SSRL gun, the APS gun is designed to be matched when the beam power is three times the cavity wall power (i.e., the normalized load impedance of the cavity without beam is $\left.\beta_{\circ} \approx 4\right)$. Neglecting those few particles that are lost on apertures inside the gun, the total power into particles is $\mathrm{JP}_{2}+\mathrm{JP}_{\mathrm{bb}}$, and thus the current density at which the matched condition holds in the steady-state is

$$
\mathrm{J}_{\mathrm{m}}=\frac{3 \mathrm{P}_{\mathrm{w}}}{\mathrm{P}_{2}+\mathrm{P}_{\mathrm{bb}}}
$$

Figure 5 shows $J_{m}$ and other results for the matched condition. The charge in each bunch of the useful beam is $Q_{m}=J_{m} Q_{b}$ and the transverse brightness is $B_{T, m}=J_{m} B_{T}$. The total RF power required is $P_{R F, m}=P_{w}+J_{m}\left(P_{2}+P_{b b}\right)$.

One sees that considerable $\mathrm{RF}$ power is required to operate in the matched condition at higher values of $E_{\mathrm{p} 2}$. In fact, more $\mathrm{RF}$ power is required than indicated in the Figure, since I have not included losses in the side-coupling cell. These losses will inevitably occur as net power flows into the first cell from the second cell via the coupling cell to supply power to accelerate the beam. Future work will include a treatment of this problem. Experiments done at SSRL indicate that the actual power requirements may be $50 \%$ higher than indicated in the Figure.

Note, however, that it is not necessary to run the gun in the matched condition. This is only the most efficient use of the RF power. If the current density is decreased below that required for a match, then the efficiency decreases, but so does the input RF power required to achieve a given value of $E_{p 2}$. Neglecting effects of the side-coupling cell, the input $R F$ power required for a current density of $\mathrm{J}$ is

$$
\mathrm{P}_{\mathrm{RF}}=\frac{\mathrm{P}_{\mathrm{w}}}{4 \beta_{\mathrm{o}}}\left(\beta_{\mathrm{o}}+1+\frac{\mathrm{J}}{\mathrm{J}_{\mathrm{m}}}\left(\beta_{\mathrm{o}}-1\right)\right)^{2}
$$

To give a more complete picture of the beam from the gun, I end this section with transverse phase-space plots for several different values of $\mathbf{E}_{\mathrm{p} 2}$. These appear in Figure 6 . 


\section{Bunch Compression Results}

After exploring various options for magnetic bunch compression[1], I have concluded that an alphamagnet-and-drift system is very difficult to beat in terms of both bunch compression and preservation of the transverse emittance. In this section, I report on preliminary results for a bunchcompressing beamline consisting of an alpha-magnet and a 2 meter drift. A more detailed analysis, including transverse effects, quadrupole focusing, and discussion of alternatives, will appear in the future.

The time-of-flight in a drift space of length $L$ is

$$
\Delta \mathrm{t}_{\mathrm{d}}=\frac{\mathrm{L}}{\beta \mathrm{c}},
$$

while the time-of-flight in an alpha-magnet is[1]

$$
\Delta t_{\alpha}=\frac{K_{\alpha}}{\beta c} \sqrt{\frac{\beta \gamma}{\nabla B}}
$$

where $\mathrm{K}_{\alpha}=1.91655 \mathrm{~m} \sqrt{\mathrm{G} / \mathrm{cm}}$ and $\nabla \mathrm{B}$ is the alpha-magnet gradient. Given the momentum, $\mathrm{p}=\beta \gamma$, and the time of exit, $\mathrm{t}_{\mathrm{ex}}$, for any particle, the time-of-arrival at the end of the driftand-alpha-magnet system is

$$
t_{a}=t_{e x}+\Delta t_{d}+\Delta t_{\alpha}
$$

The program alpha_opt uses this equation to find the optimum value of $\nabla \mathbf{B}$ for a given set of $\left(t_{e x}, p\right)$ pairs. For present purposes, I define "optimum" to mean that condition where the spread in $t_{a}$ is minimized. For any value $E_{p 2}$, a set of $\left(t_{e x}, p\right)$ pairs can be generated by running rfgun. Data for $E_{\mathrm{p} 2}$ between 50 and $80 \mathrm{MV} / \mathrm{m}$, and a cathode radius of $3 \mathrm{~mm}$, is shown in Figure 7, where I present histograms of the time and momentum distributions as well as $\left(t_{e x}, p\right)$ for individual simulation particles.

Figure 8 shows the results of running alpha_opt on the data of the previous Figure. The best results are achieved for $\mathrm{E}_{\mathrm{p} 2}=60 \mathrm{MV} / \mathrm{m}$, a result of choosing 2 meters for the drift-length. (Note that the optimal drift length for the lowest emittance beam $\left(E_{\mathrm{p} 2}=70 \mathrm{MV} / \mathrm{m}\right)$ is about 8 meters, which is impractically long.)

Figure 9 shows various parameters before and after compression. $\Delta t_{j}$ and $\Delta t_{f}$ are, respectively, the initial and final bunch lengths. Also, shown are the alpha-magnet gradient and $x_{\max }$, the maximum extent of the trajectory inside the alpha-magnet.

\section{Acknowledgements}

I wish to thank Eiji Tanabe of AET for helpful discussion and ideas about the new design.

\section{References}

[1] M. Borland, A High-Brightness Thermionic Microwave Electron Gun, Stanford University $\mathrm{Ph} . \mathrm{D}$. Thesis, 1991.

[2] E. Tanabe, et. al., "A 2-MeV Microwave Thermionic Gun", SLAC-PUB-5054.

[3] M. Borland, et. al., "Performance of the $2 \mathrm{MeV}$ Microwave Gun for the SSRL $150 \mathrm{MeV}$ Linac", in Proceedings of the Linear Accelerator Conference, September, 1990. Also SLAC-PUB-5333. 
[4] U. Laustroer, et. al., "URMEL and URMEL-T User Guide", DESY-M-83-03, February 1987.

[5] K. Halbach, R. F. Holsinger, "SUPERFISH-A Computer Program for Evaluation of RF Cavities with Cylindrical Symmetry, Particle Accelenators, 7:213-222, 1976.

[6] E. Tanabe, private communication.

[7] M. Borland, "rfgun: A Program to Simulate RF Guns", SSRL ACD-Note 78, March 13, 1991.

[8] A. T. Drobot, et. al., "Numerical Simulation of High Power Microwave Sources", IEEE Trans., 32: 2733-7, 1985. 


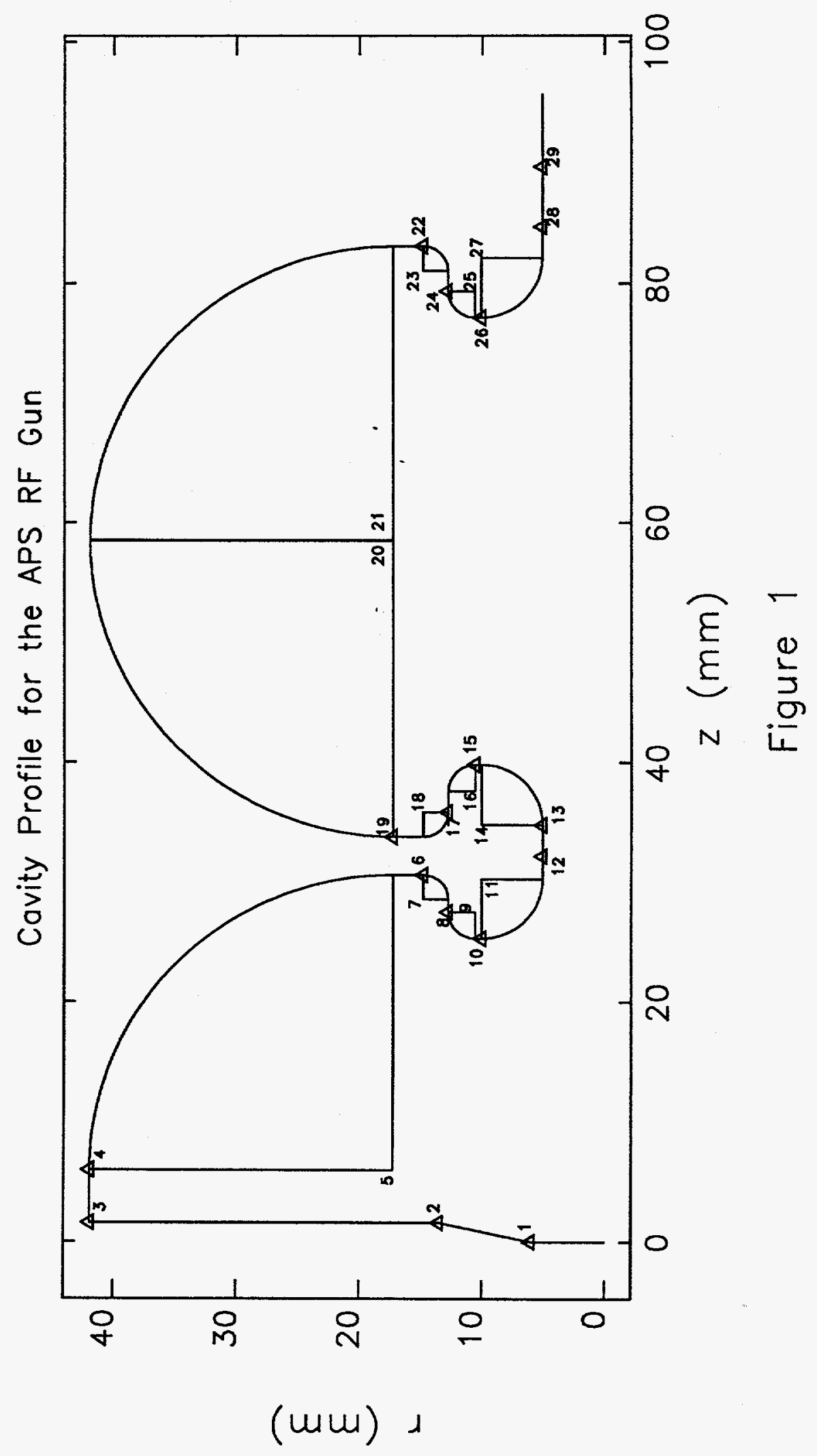



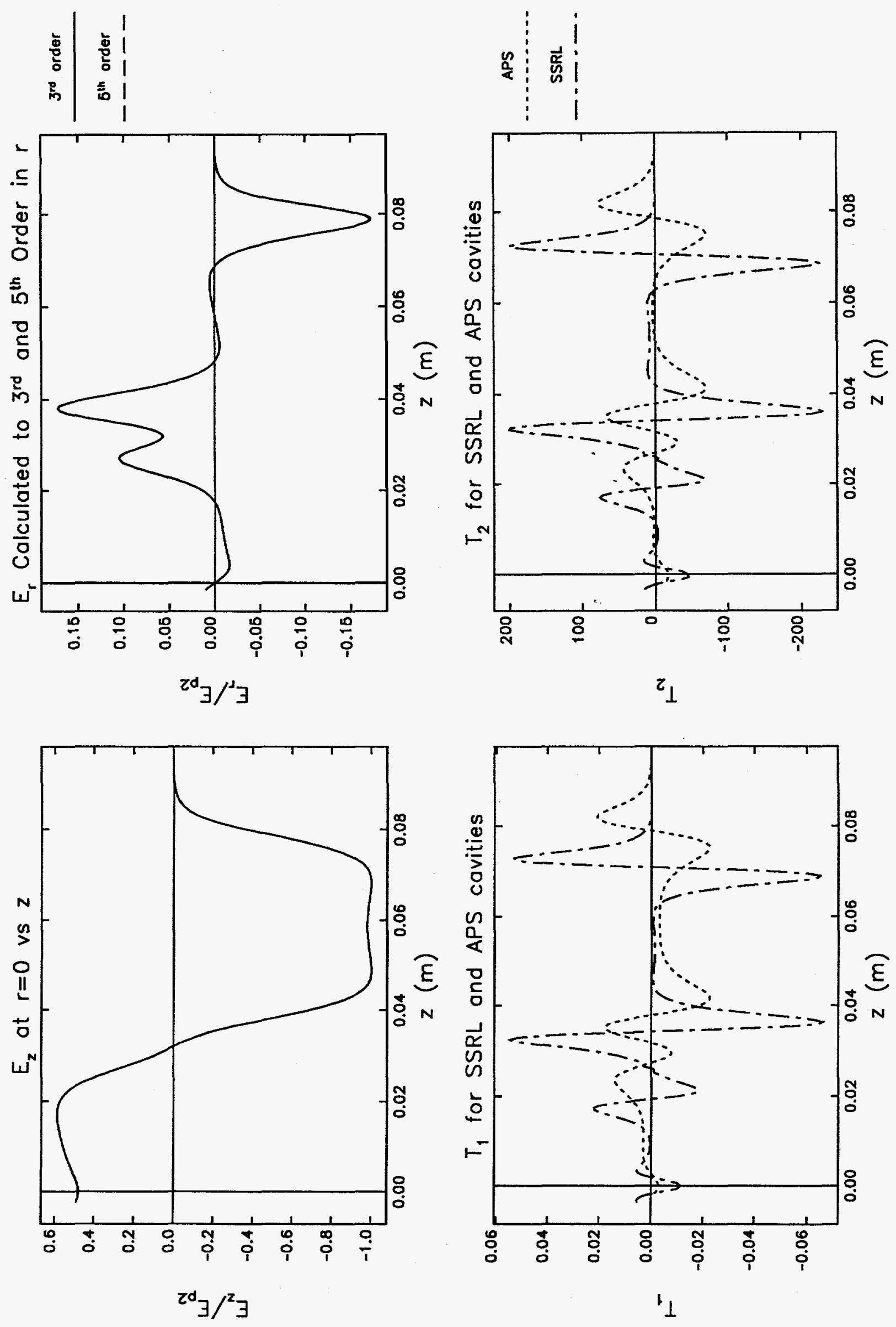

0
$\frac{1}{2}$
$\frac{0}{2}$ 


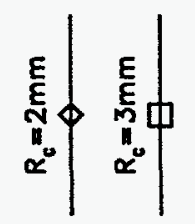
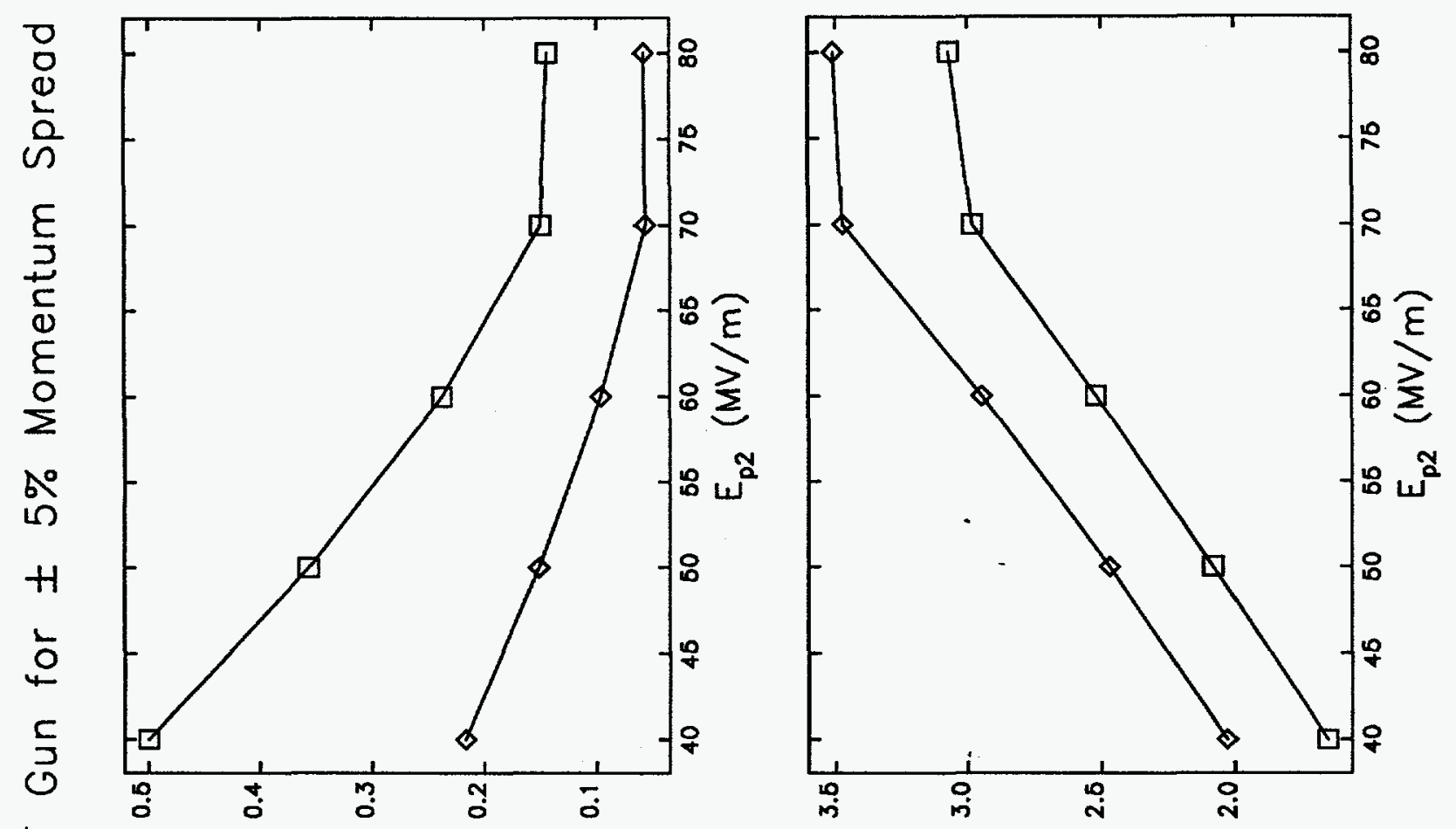

$M$

$\frac{L}{\alpha}$

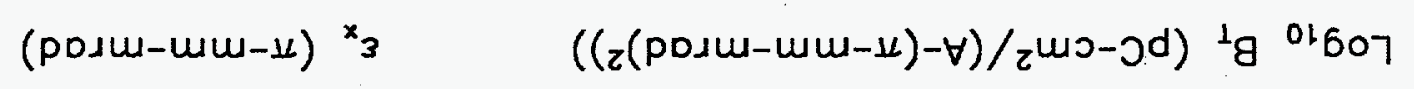

$\frac{1}{3}$

$\stackrel{n}{\alpha}$

๖ั
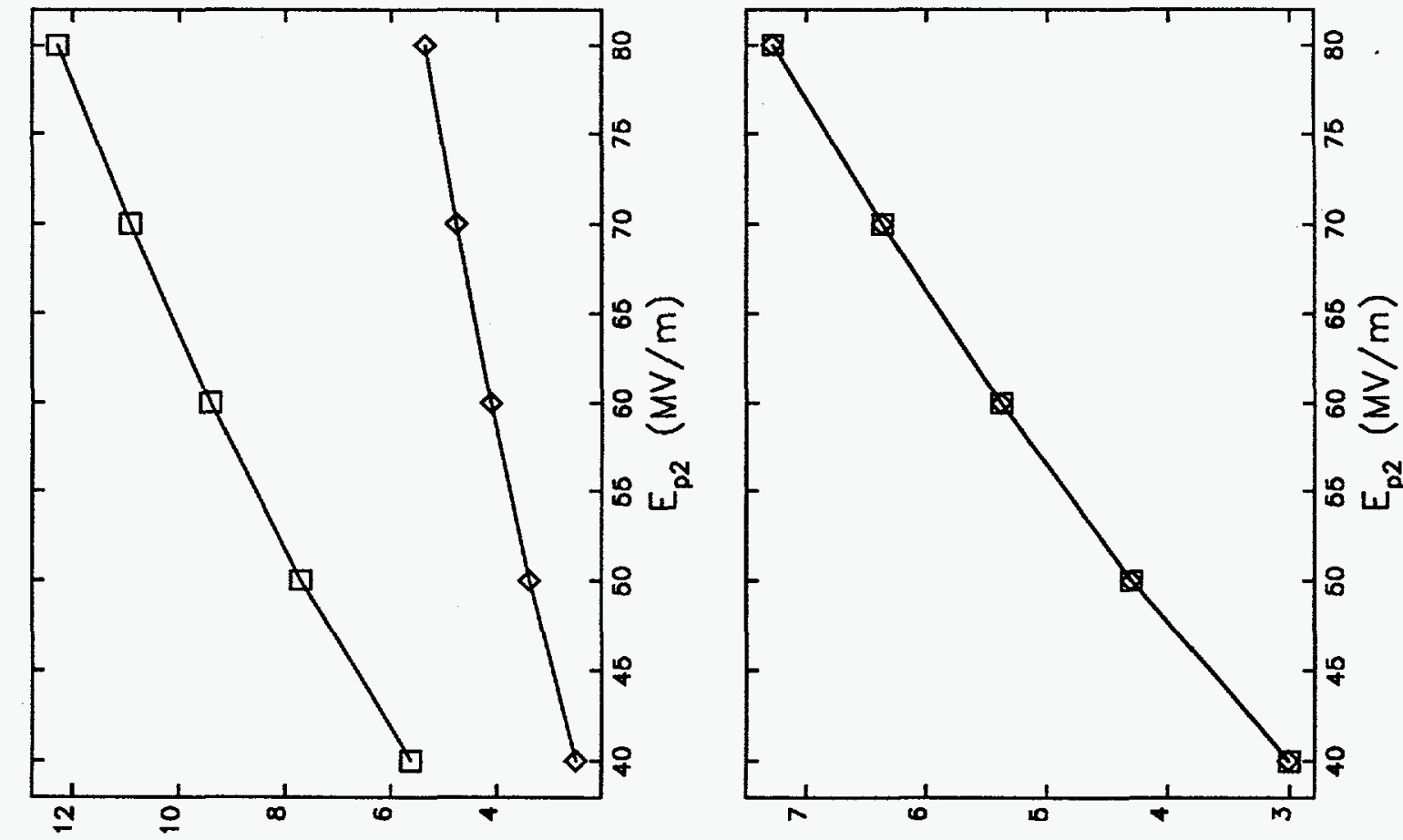

$\left(\left(\tau^{w o / \forall) / \partial d}\right)^{a} 0\right.$

$\langle\lambda g\rangle$ 


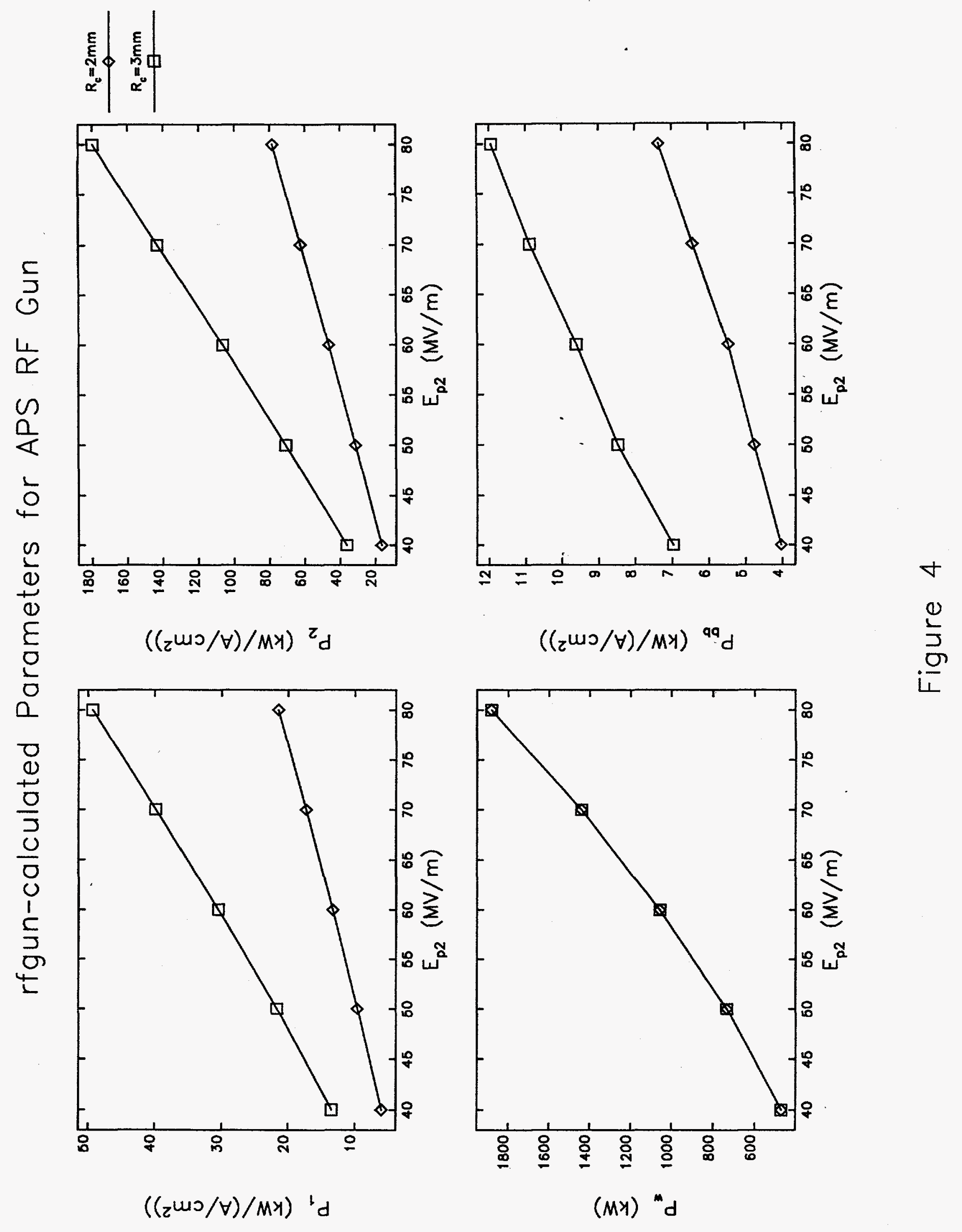


है है है
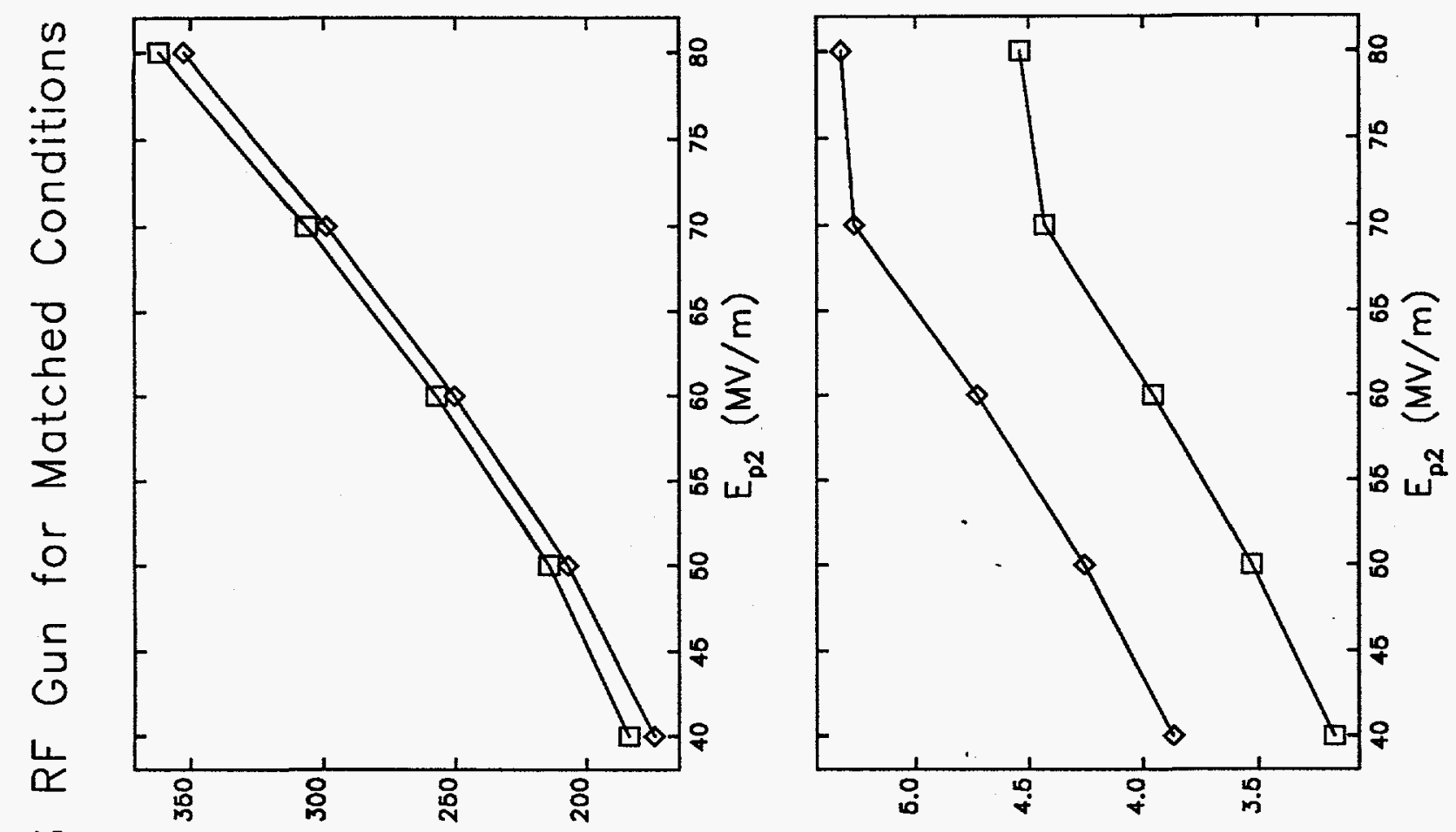

$\stackrel{n}{4}$

(od) ${ }^{w_{0}}$

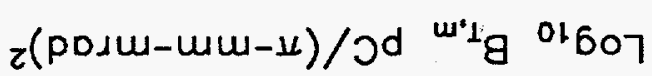

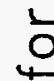
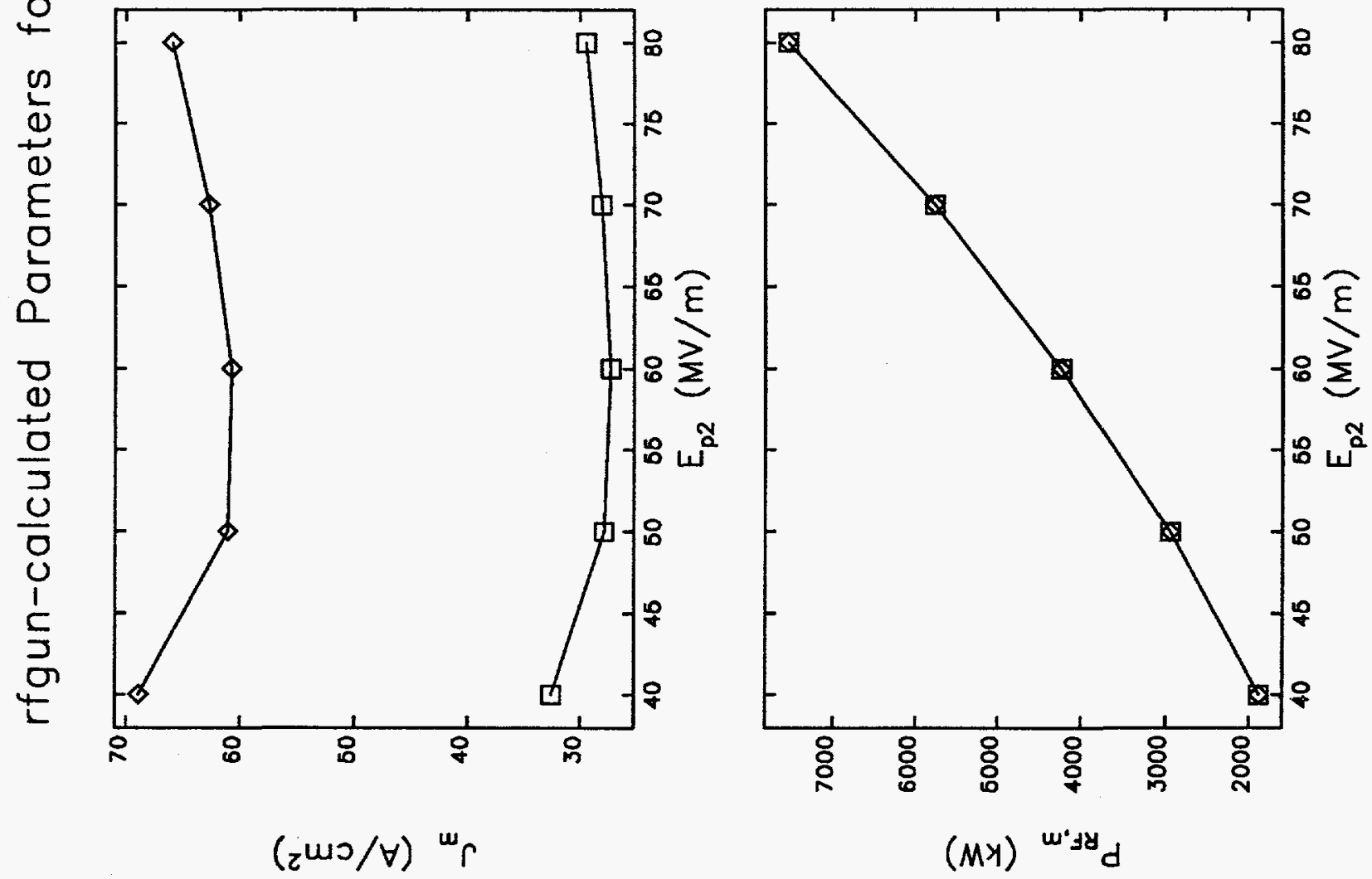

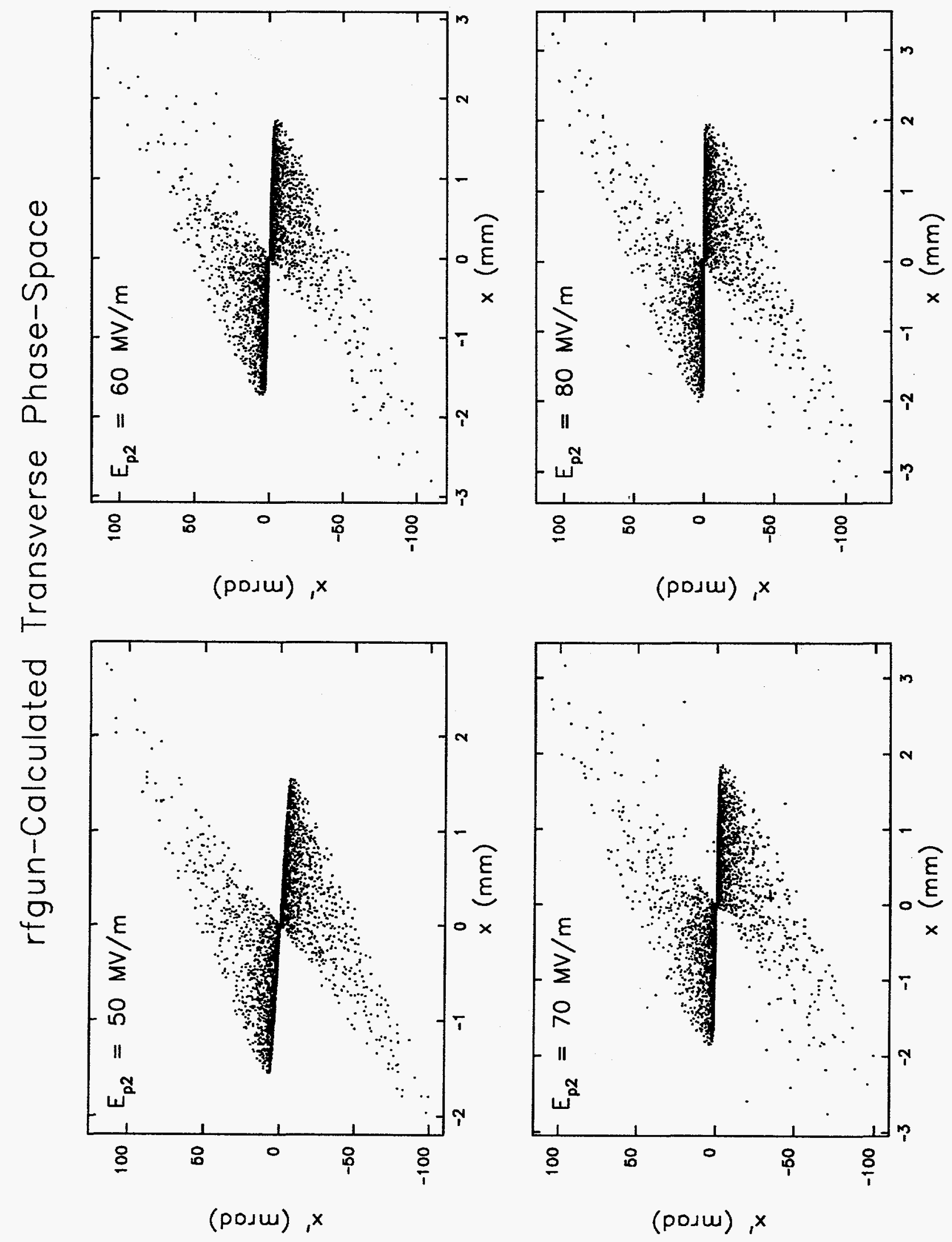

0
$\frac{1}{5}$
$\frac{5}{4}$ 


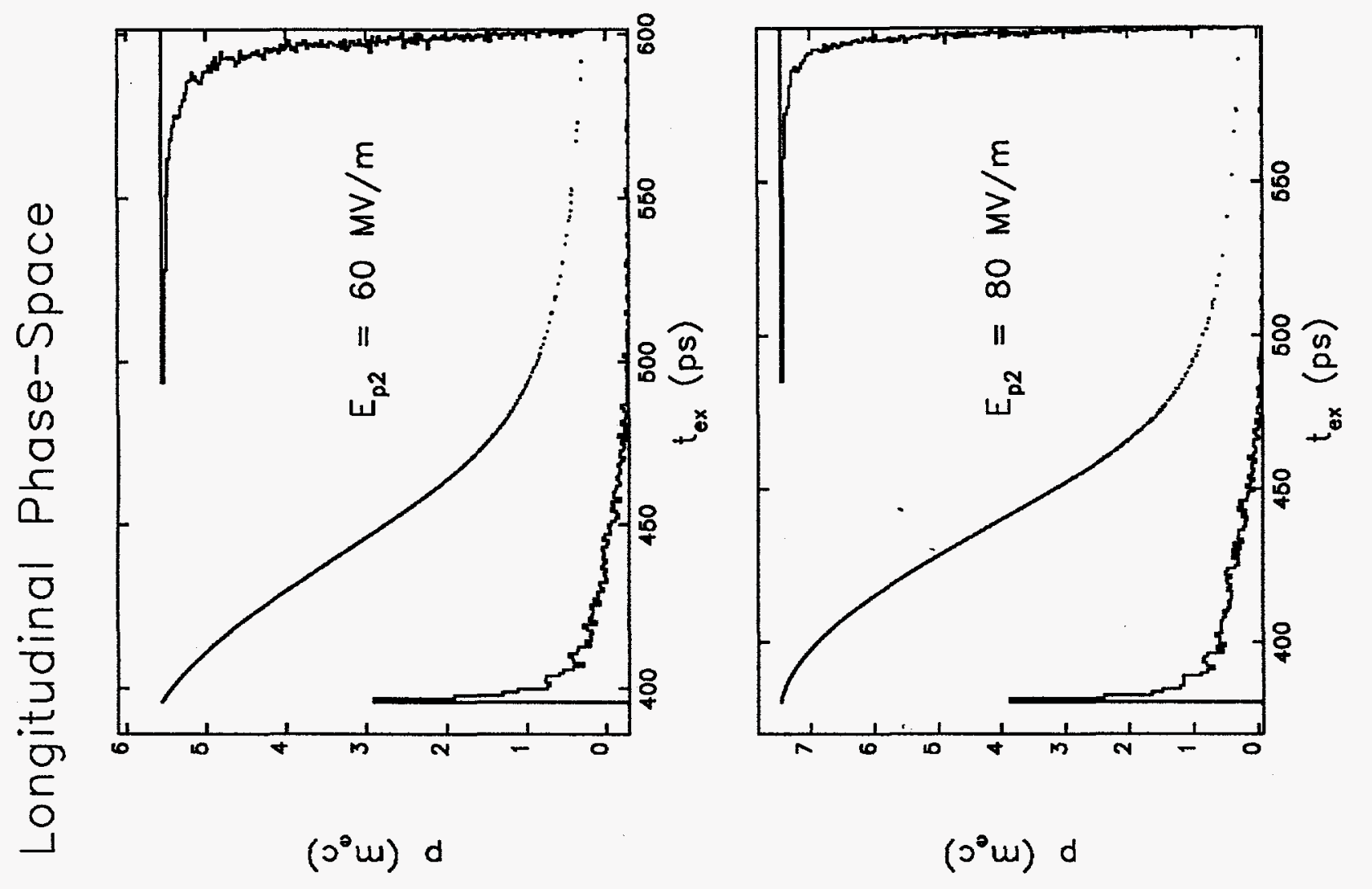

N
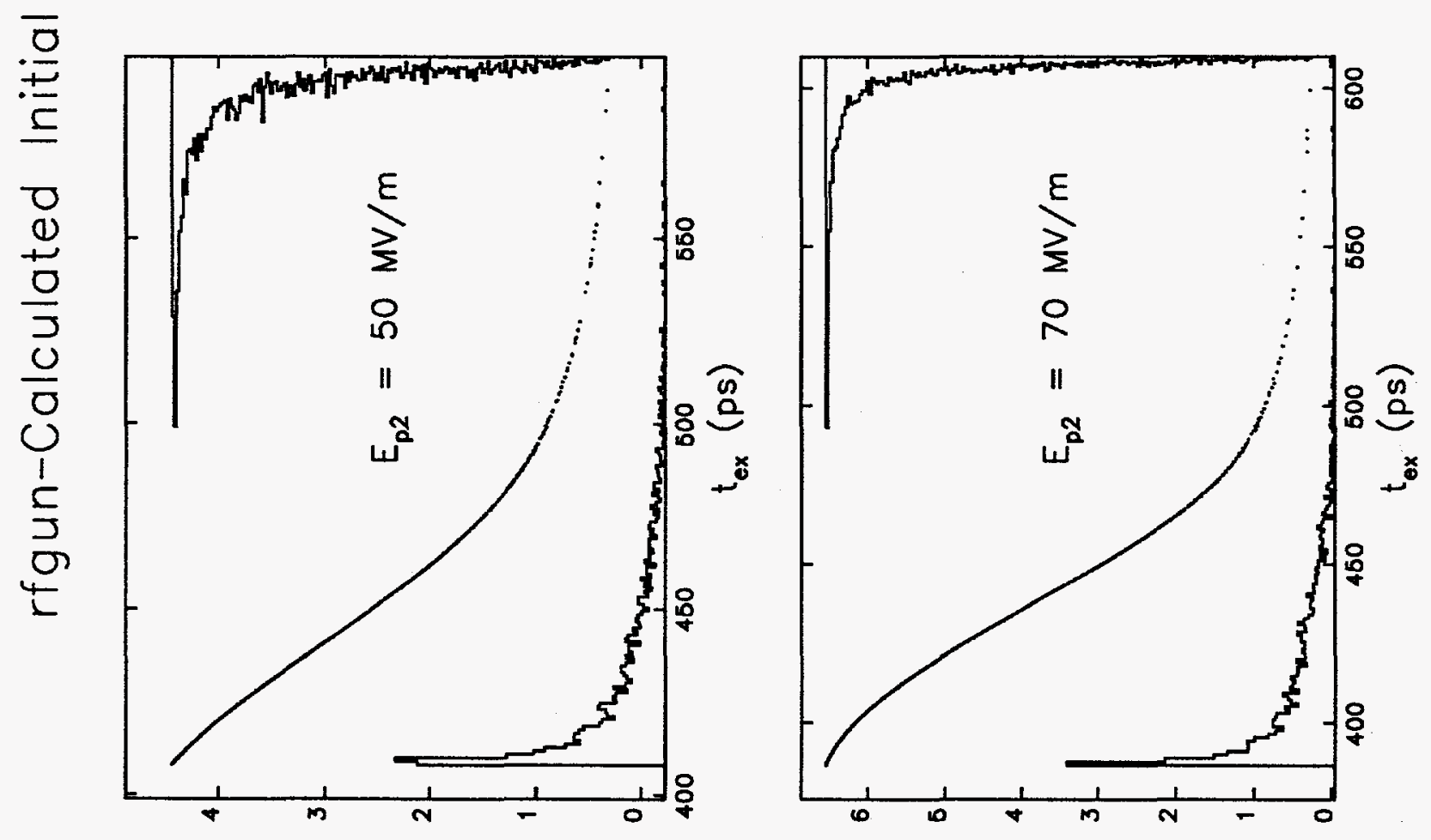

$\left(o^{2} u\right) d$

$\left(0^{2} m\right) d$ 

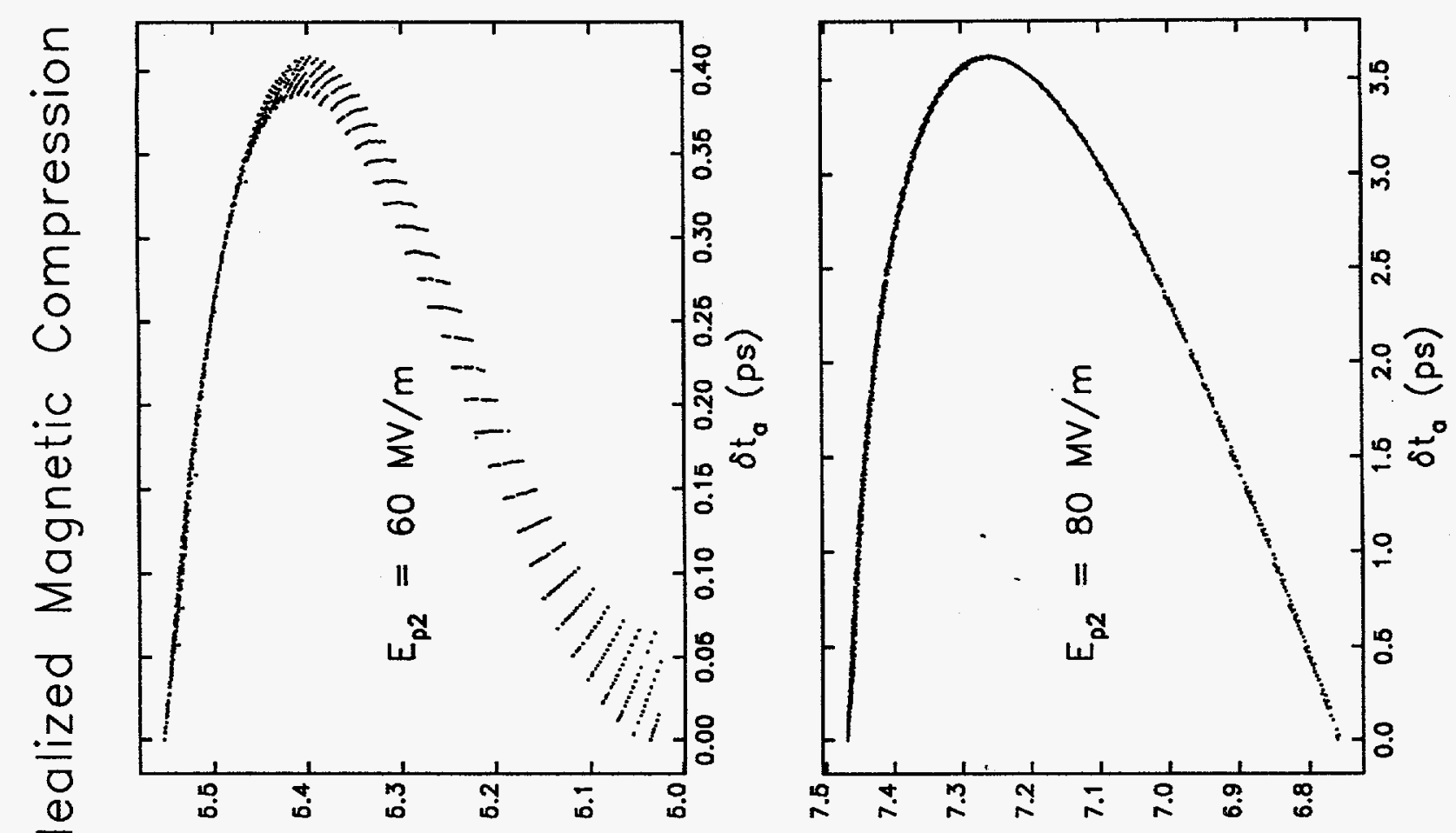

$\infty$
$\frac{0}{J}$
$\frac{0}{1}$

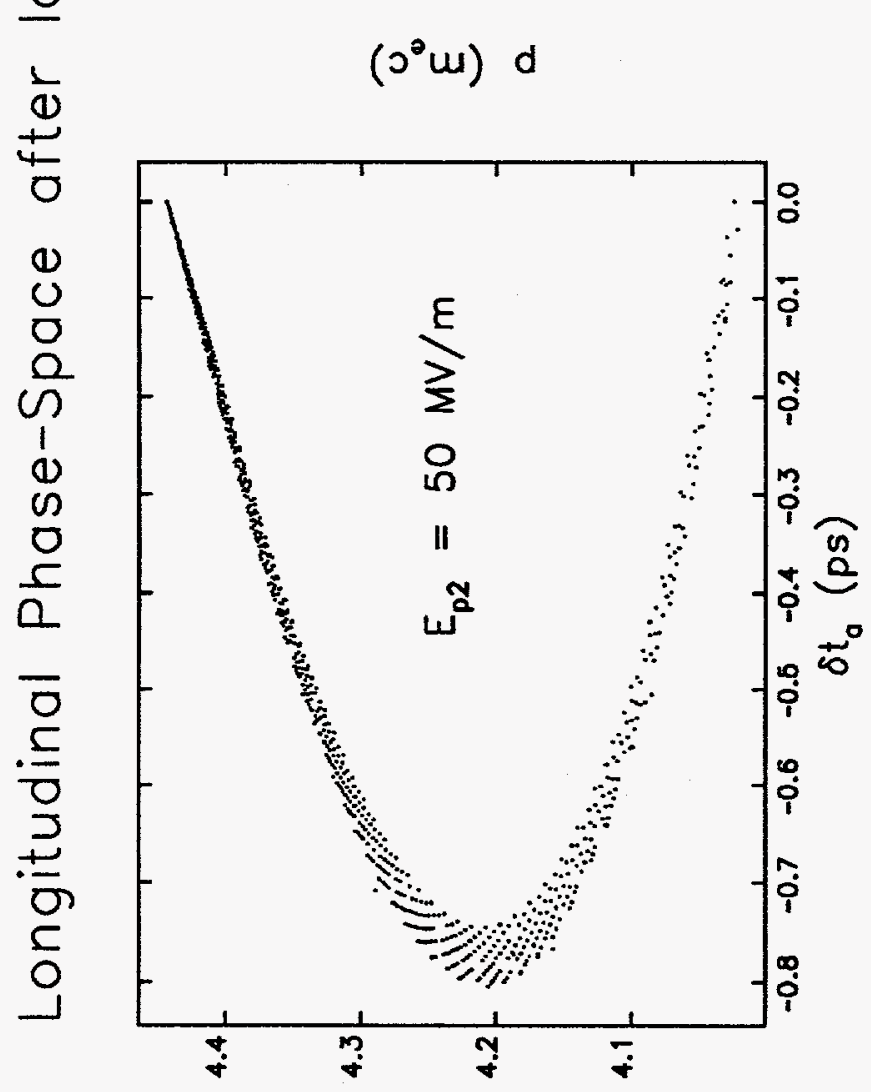

$\left(0^{\circ} w\right) d$

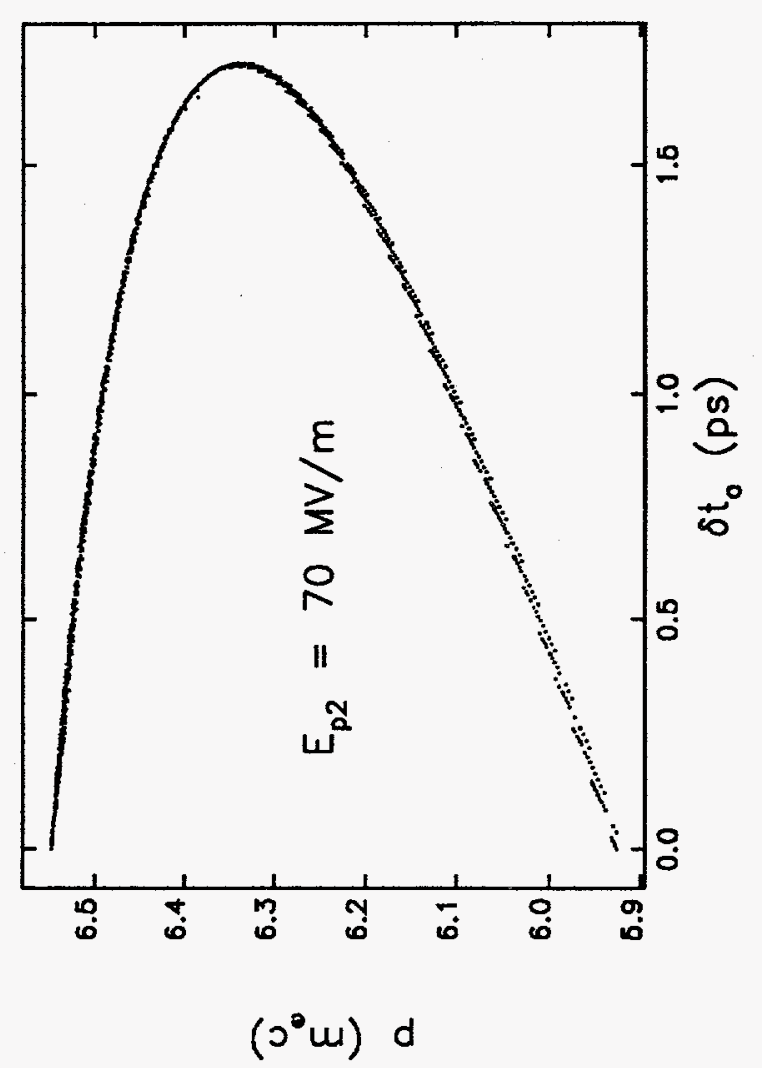



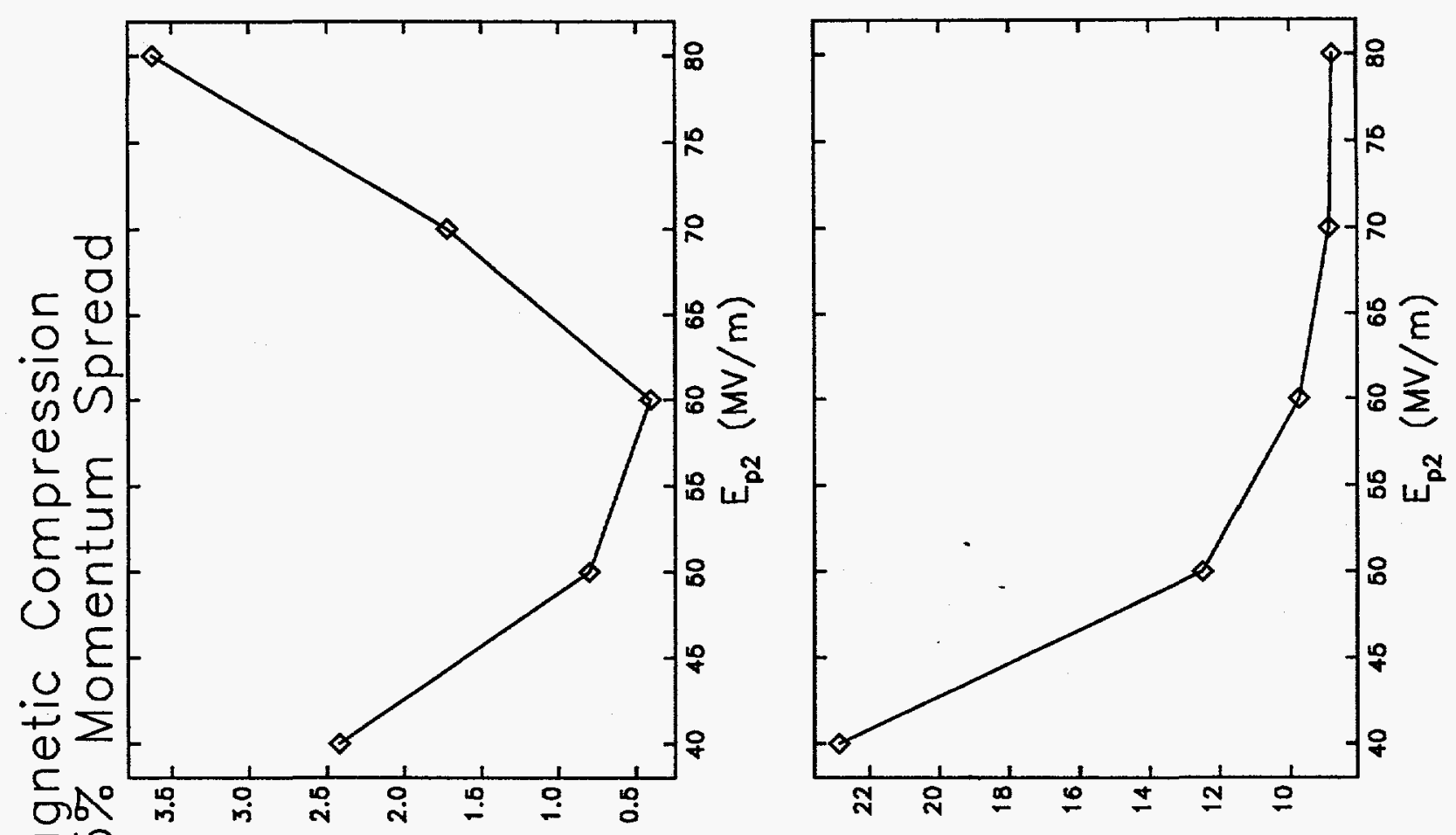

0
$\frac{1}{J}$
$\frac{0}{4}$ $\sum^{\circ}$

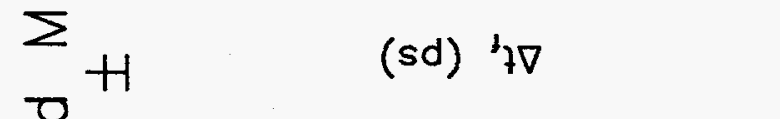

(wo) ${ }^{x o m} x$

01

$\stackrel{N}{0} \div$

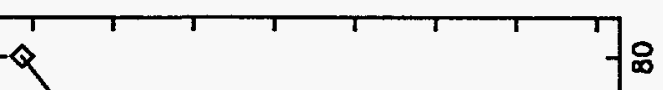

으 $\frac{1}{5}$

40

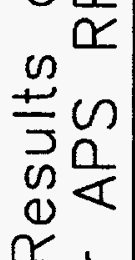
$\propto$ 는

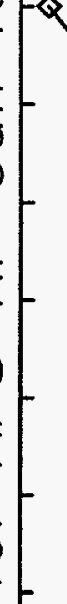

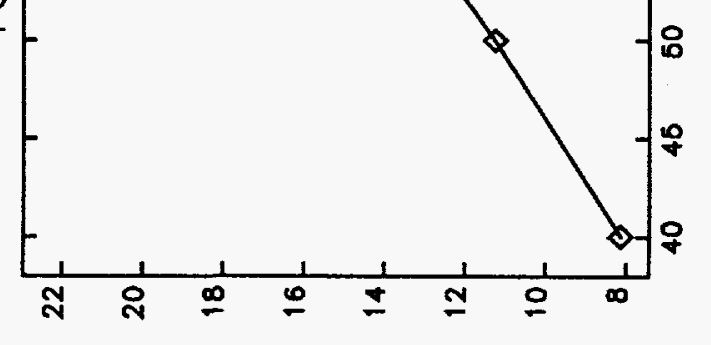

(sd) $7 \nabla$

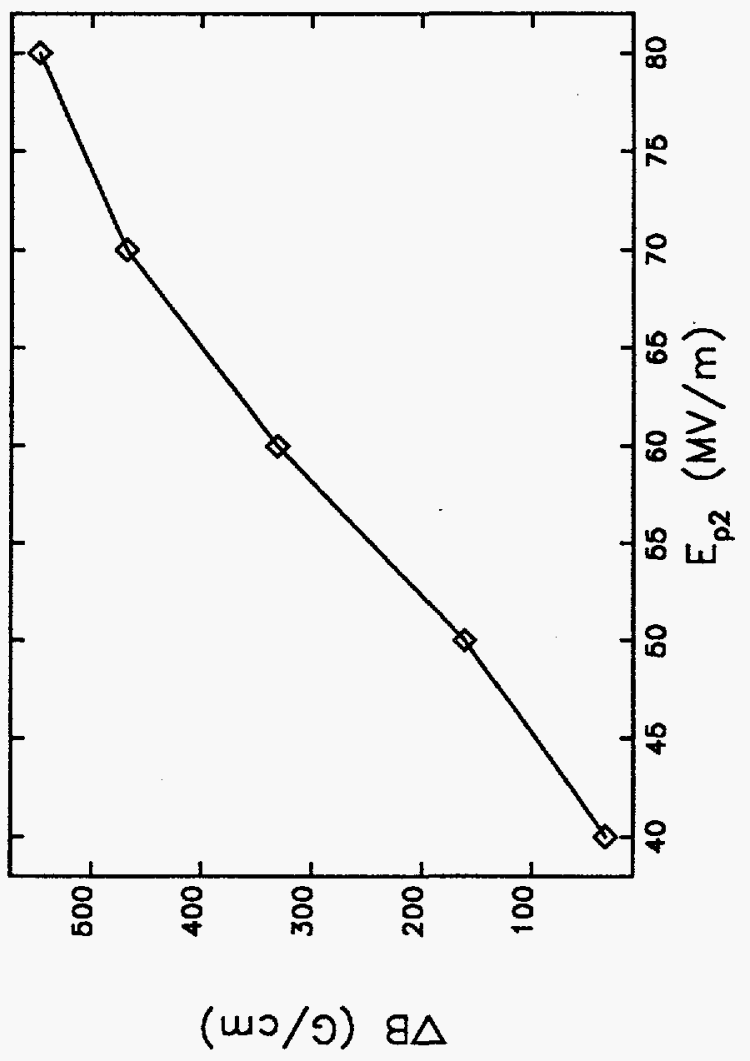


Table 1: Geometry of the APS RF Gun

\begin{tabular}{|c|c|c|c|c|c|}
\hline label & type & Z & $\mathbf{r}$ & radius & angle \\
\hline & & $\mathrm{mm}$ & $\mathrm{mm}$ & $\mathrm{mm}$ & deg \\
\hline 1 & point & 0.00 & 6.00 & $\mathrm{n} / \mathrm{a}$ & $\mathrm{n} / \mathrm{a}$ \\
\hline 2 & point & 1.60 & 13.50 & $n / a$ & $\mathrm{n} / \mathrm{a}$ \\
\hline 3 & point & 1.60 & 41.91 & $n / a$ & $n / a$ \\
\hline 4 & point & 6.00 & 41.91 & $\mathrm{n} / \mathrm{a}$ & $\mathrm{n} / \mathrm{a}$ \\
\hline 5 & arc & 6.00 & 17.27 & 24.64 & 0 \\
\hline 6 & point & 30.64 & 14.818 & $\mathrm{n} / \mathrm{a}$ & $n / a$ \\
\hline 7 & arc & 28.61 & 14.818 & 2.03 & 270 \\
\hline 8 & point & 27.50 & 12.788 & $n / a$ & $\mathrm{n} / \mathrm{a}$ \\
\hline 9 & arc & 27.50 & 10.588 & 2.20 & 180 \\
\hline 10 & point & 25.30 & 10.08 & $\pi / a$ & $\mathrm{n} / \mathrm{a}$ \\
\hline 11 & arc & 30.30 & 10.08 & 5.00 & 270 \\
\hline 12 & point & 32.24 & 5.08 & $n / a$ & $n / a$ \\
\hline 13 & point & 34.81 & 5.08 & $\mathrm{n} / \mathrm{a}$ & $\mathrm{n} / \mathrm{a}$ \\
\hline 14 & arc & 34.81 & 10.08 & 5.00 & 0 \\
\hline 15 & point & 39.81 & 10.588 & $\mathrm{n} / \mathrm{a}$ & $\mathrm{n} / \mathrm{a}$ \\
\hline 16 & arc & 37.61 & 10.588 & 2.20 & 90 \\
\hline 17 & point & 35.87 & 12.788 & $\mathrm{n} / \mathrm{a}$ & $\mathrm{n} / \mathrm{a}$ \\
\hline 18 & $\operatorname{arc}$ & 35.87 & 14.818 & 2.03 & 180 \\
\hline 19 & point & 33.84 & 17.27 & $\mathrm{n} / \mathrm{a}$ & $\mathrm{n} / \mathrm{a}$ \\
\hline 20 & arc & 58.48 & 17.27 & 24.64 & 90 \\
\hline 21 & arc & 58.48 & 17.27 & 24.64 & 0 \\
\hline 22 & point & 83.12 & 14.818 & $\mathrm{n} / \mathrm{a}$ & $n / a$ \\
\hline 23 & $\operatorname{arc}$ & 81.09 & $\overline{14.818}$ & 2.03 & 270 \\
\hline 24 & point & 79.35 & 12.788 & $\mathrm{n} / \mathrm{a}$ & $\mathrm{n} / \mathrm{a}$ \\
\hline 25 & arc & 79.35 & 10.588 & 2.20 & 180 \\
\hline 26 & point & 77.15 & 10.08 & $n / a$ & $\mathrm{n} / \mathrm{a}$ \\
\hline 27 & arc & 82.15 & 10.08 & 5.00 & 270 \\
\hline 28 & point & 84.72 & 5.08 & $\mathrm{n} / \mathrm{a}$ & $n / a$ \\
\hline 29 & point & 89.72 & 5.08 & $\mathrm{n} / \mathrm{a}$ & $n / a$ \\
\hline
\end{tabular}

Table 2: Cell Parameters Calculated with URMEL

\begin{tabular}{|l|c|c|c|}
\hline quantity & Cell 1 & Cell 2 & unit \\
\hline length & 3.224 & 5.248 & $\mathrm{~cm}$ \\
\hline $\mathrm{Q}$ & 12500 & 17042 & \\
\hline Shunt Impedance & 1.57 & 3.63 & $\mathrm{M} \Omega$ \\
\hline $\mathrm{E}_{\mathrm{ps}} / \mathrm{E}_{\mathrm{pi}}$ & 1.78 & 1.75 & \\
\hline $\mathrm{E}_{\mathrm{c}} / \mathrm{E}_{\mathrm{pi}}$ & 0.830 & $\mathrm{n} / \mathrm{a}$ & \\
\hline $\mathrm{K}_{\mathrm{i}}$ & 0.143 & 0.212 & $\mathrm{~mJ} /(\mathrm{MV} / \mathrm{m})^{2}$ \\
\hline
\end{tabular}

